\title{
The relationship between treatment of mental disorder and chronic tinnitus
}

\author{
Seyed Kazem Malakouti' \\ Saeid Mahmoudian² \\ Jafar Filli ${ }^{3}$ \\ Marzieh Nojomi ${ }^{4}$ \\ Mahshid Rabetian ${ }^{3}$
}

\begin{abstract}
Introduction: Comorbidity of chronic tinnitus and mental disorders may result in more disability. Objectives: This research provides an evaluation about the effects of medically treated comorbid mental disorder on chronic tinnitus. Materials and Methods: Fifty-five patients diagnosed with chronic tinnitus and mental disorders were randomly requited by producing a before-after design. They underwent three months of drug therapy for comorbid mental disorders by psychiatrists. Study instruments are Tinnitus Handicap Inventory, Tinnitus Questionnaire, Loudness Match Tinnitus, Hamilton Depression Rating Scale, Beck Anxiety Inventory, The Structured Clinical Interview and Symptom Check List -90. Results: Three months medical treatment puts forward the argument that among mental disorders, anxiety and major depressive disorder demonstrate a significant reduction. Pearson Correlation coefficient ostensibly reveals that there is no significant relationship between mental disorders and tinnitus severity. The statistics lend support to profound effect of major depressive disorder as a key factor on tinnitus disability exacerbation. Medical treatment also touches on issue such as tinnitus severity, its disabling effects and TQ subscales that statistics shows significant trends in their reduction. Conclusion: Findings lay emphasis on tinnitus severity reduction and connection might be established between alleviated mental disorders comorbidity and the improvement of quality of life.
\end{abstract}

Keywords: comorbidity, mental disorders, tinnitus.

\footnotetext{
${ }^{1}$ Department of Psychiatry and Tehran Psychiatric Institute, Mental Health Research Centre - Iran University of Medical Sciences (IUMS), Tehran, Iran. - Tehran Germany. E-mail: malakoutik@gmail.com

${ }^{2}$ Laboratory for Auditory Neuroscience, ENT and Head \& Neck Research Center and Otorhinolaryngology Department - Iran University of Medical Sciences (IUMS),

Tehran, Iran; and Hanover Medical University (MHH), Hanover, Germany. - Hannover - Germany. E-mail: saeid.mahmoudian@gmail.com

${ }^{3}$ ENT and Head \& Neck Research Center - Iran University of Medical Sciences (IUMS), Tehran, Iran. - Tehran - Germany. E-mail: jafar.fili@gmail.com.

E-mail: Mrabetian@yahoo.com

${ }^{4}$ Department of Community Medicine, School of Medicine - Iran University of Medical Sciences (IUMS), Tehran, Iran - Tehran - Germany.

E-mail: mnojomi@tums.ac.ir

Institution: ENT and Head \& Neck Research Center; Iran University of Medical Sciences (IUMS), Tehran, Iran.

Send correspondence to:

Jafar Filli.

ENT and Head \& Neck Research Center; Iran University of Medical Sciences (IUMS), Hazrate Rasoul Medical Complex, Niayesh St., Sattarkhan Ave., Tehran, Iran.

Tel: +98 21 66504294. fax: +98 21 66525329. E-mail address: jafar.fili@gmail.com

Paper submitted to the ITJ-SGP (Publishing Management System) on July 31, 2013;

and accepted on August 31, 2013. cod. 134.
} 


\section{INTRODUCTION}

The word tinnitus originates from the Latin word "tinnier" which means tinkling or ringing ${ }^{1}$. It is perception of a sound without existence of an external stimulus ${ }^{2}$. Tinnitus is a common complaint, usually subjective, perceived only by the patient; thus, diagnosis and monitoring rely basically on self-report ${ }^{3}$. Tinnitus of the same level may be regarded as a problem by a subject while it may be even unrecognizable for another subject ${ }^{4}$. The prevalence of tinnitus varies from $3 \%$ to $30 \%$ depending on the definition of tinnitus and the study group ${ }^{3}$. Patients who experience tinnitus often report significant accompanied morbidities such as sleep deprivation, lifestyle detriment, emotional disturbances, work difficulties, social interaction problems, and decreased overall health ${ }^{5-7}$. Although causative relations are yet unrevealed, patients with tinnitus are at increasing risk for depression, anxiety and insomnia $5,8,9$. It is indicated that $48 \%$ to $60 \%$ of patients suffering chronic and disabling tinnitus have major depressive disorder (MDD) ${ }^{10-12}$. Asplund reported poor sleep and frequent waking to be more common among chronic tinnitus patients than the general population in both sexes $^{13}$. Many clinical trials have been performed in order to evaluate the efficacy of psychotropic agents on tinnitus so far. Clonazepam and antidepressants such as nortriptyline and amitriptyline have been proved to be effective in reducing the severity of the problem and improving the quality of life of tinnitus patients ${ }^{14-18}$. The studies have illustrated that Benzodiazepines and GABA-egric agents may decrease the severity of tinnitus and the SPECT evaluation has proved that the brain blood flow increases objectively in tinnitus ${ }^{19}$. Using SSRIs has been successful in reducing the severity of tinnitus by lowering the conduction of impulse of tinnitus ${ }^{20,21}$.

The aim of this study is to determine the impact of treatment of Comorbid mental disorders accompanied chronic tinnitus on the outcomes of the tinnitus symptom. This study was performed in the ENT and Head \& Neck Research Center, Hazrate Rasoul Medical Complex, Iran University of Medical Sciences, Tehran, Iran.

\section{MATERIALS AND METHODS}

\section{Subjects and setting}

This study was conducted by creating a before-after design in two discrete phases during August 2009 and 2010. In the first phase in order to investigate the prevalence of mental disorder in tinnitus, amongst 2350 patients suffering from tinnitus registered at the ENT and Head \& Neck Research Center of Hazrate Rasule General Hospital, 400 patients over 18 years old, were clinically interviewed by well-trained psychiatrists ${ }^{22}$. In the second phase from among aforementioned 400 patients, the ones suffering from comorbid mental disorder on tinnitus were selected. We considered type one and type two errors 0.05 and 0.2 respectively to detect a standardized difference of moderate $(S D=0.5)$ between before and after intervention on Tinnitus handicap Index (THI). Therefore Among patients with tinnitus, 55 subjects were randomly selected for the study. Tinnitus patients with serious physical diseases or psychotic disorders were excluded. None of the study subjects had taken any medication for their tinnitus including psychotropic or antiepileptic agents since a long period before being included in the study.

\section{Measures and questionnaires}

The Structured Clinical Interview for DSM-III-R, axis I psychiatric disorders (SCID). The Structured Interview for DSM-III-R (SCID-I) was applied as a diagnostic instrument for DSM-III-R axis I psychiatric disorders to identify mental disorders. The interview was conducted by well-trained psychiatric residents in the SCID procedure. The Farsi version was provided with test-retest reliability (Yule's Y) for diagnosis of all current and life-time disorders of 0.61 to 0.63 and for inter-rater reliability (kappa statistics) for all current and life-time disorders of 0.52 to 0.55 respectively ${ }^{23}$.

\section{Persian Tinnitus Handicap Inventory (P-THI)}

The P-THI measures the impact of measures and tinnitus on daily life, which had been developed by Newman et al. with a high reliability (Cronbach's Alpha $=0.93)^{23}$. Three of the functional effects, the emotional response and the catastrophic response to tinnitus were described. The cut-off point in THI score was defined as 38 to discriminate between slight/mild versus moderate or more intensive tinnitus as a severity index ${ }^{24}$.

\section{Persian Tinnitus Questionnaire (P-TQ)}

It was created to evaluate the behavioral side effects of tinnitus. The subscales consist of auditory perception difficulties, sleep problems, somatic complaints, and emotional and cognitive disturbances ${ }^{25}$, with Cronbach's Alpha of 0.95 and the test-retest reliability between $0.91-0.94$. The subjects with chronic severe tinnitus having scores more than $44 \%$ in TQ-P were enrolled in the study. Improvement or worsening of condition was determined by patients' declaring a change in tinnitus of at least $40 \%$.

\section{Symptom Check List -90-Revised (SCL-90-R)}

The SCL-90-R is a 90-item self-report system inventory developed by Derogatis in the $1980 \mathrm{~s}^{26}$. The global severity index (GSI), is one of the three global indexes which measures the extent or depth of the individual's psychiatric disturbances. Based on the study of Noorbala et al. ${ }^{27}$, we used the cutoff point of 0.7 for GSI. 


\section{Tinnitus Assessment}

Pitch and Loudness Match tinnitus (PMT and LMT) was evaluated in tinnitus subjects using an external tone presented to the contra lateral ear. This task was accomplished using a Tinnitus Evaluation Device $\left(\right.$ TinnED $^{\circledR}$ ) which includes 6 channels to reconstruct the Most Troublesome Tinnitus (MTT) with a similar frequency and intensity. The accuracy of the calibrating equipment should be sufficient to determine whether the TinnED $^{\circledR}$ is within the tolerances permitted by American Standard Specification for Audiometers, S3.6-2004. For PMT test, we used a two-alternative forced-choice method. LMT was obtained at each of the test tones used in the pitch-matching procedure. Subsequently, with the auditory threshold level at that frequency, the sound was increased in 1-dB steps until a patient reported that the external tone equaled the loudness of the tinnitus. The subjects had to have LMT over 6 decibel sensation level (dB SL) to be included in this study. The least objective score was $\pm 2 \mathrm{~dB}$ sensation level (SL) which is considered important clinically ${ }^{28}$.

\section{Hamilton depression scale (HDS)}

HDS is an observer-rated depressive symptom rating scale. The version with 17 items was scored in this study. Items with quantifiable severity were ranked on a scale of 0-4 and those measuring symptoms that weredifficult to assess reliably were ranked on a scale of $0-2^{29}$.

\section{Beck Anxiety Inventory (BAI)}

BAI is a 21 -item self-reporting scale ${ }^{30}$ developed to measure the severity of anxiety. Each item gets scores ranging from 0-3. The Farsi version has been used in several studies ${ }^{31}$.

\section{Study Conduct}

The registry system of ENT and Head \& Neck Research Center were used in this study. Simple randomization was used to recruit the study sample one out of each seven subjects. In the case of absence or any other reasons, the next registry would be contacted by telephone and invited to participate in the study. After obtaining a fully informed consent from each study subject, and having evaluated and completed the study instruments, they were entered into study. The main goal of this study is the medical therapy of psychiatric disorders but not tinnitus. Patients were separately visited by two psychiatrists. The selection of medicine category was on the basis of disorder type and its severity.

In anxiety disorders according to its severity citalopram tablet up to $40 \mathrm{mg} / \mathrm{d}$ accompanied by either clonazepam tablet up to $1 \mathrm{mg} / \mathrm{d}$ or propranolol tablet up to $30 \mathrm{mg} / \mathrm{d}$, in depressive disorders based on its severity sertraline tablet up to $100 \mathrm{mg} / \mathrm{d}$ with or without nortriptyline up to $25 \mathrm{mg} / \mathrm{d}$, in bipolar disorders sodium valproate tablet up to $600 \mathrm{mg} / \mathrm{d}$, in eating disorder fluoxetine capsule up to $40 \mathrm{mg} / \mathrm{d}$ and in somatoform disorders sertraline tablet up to $100 \mathrm{mg} / \mathrm{d}$ were prescribed. Each patient was contacted regularly in order to be reminded about the next visit. Each of the study subjects was visited at the time of zero, two and four weeks later, then eight and twelve weeks later from the time of zero. Each subject was under examination for three months. All of the subjects remained in the study and followed their medical prescriptions for three months.

This study has been approved by the Ethical Committee of ENT and Head \& Neck Research Center, Iran University of Medical Sciences (IUMS) code number of MT-4250.

\section{Statistics methods}

All analyses were accomplished using SPSS software package version 16.0 (SPSS, Inc. Chicago, IL). We applied Kolmogorov Smirnov as a method for testing the normality of distribution ofcontinuous variables, which demonstrated that all the numeric variables had normal distributions $(P>0.05)$. Paired sample $t$-test, and McNemar test were conducted to compare variables before and after intervention. Pearson correlation was also applied to assess the correlation between tinnitus index and depression/anxiety scales. Significance level was considered 0.05 .

\section{RESULTS}

\section{Demographic features}

Demographic features of the study sample have been demonstrated in Table 1. The mean age is 49.7 $(S D=12.5)$ with a minimum of 19 and a maximum of 73 .

\section{Psychological features and prevalence of mental disorders}

The psychological features of the study sample have been revealed in Table 2 . The results of comparing the mean scores of the psychological indexes yielded before and after treatment; show that the pharmacotherapy has been significantly successful in reducing the severity of the psychological symptoms.

The prevalence of mental disorders yielded from SCID among the study subjects is shown in Table 3 . The most prevalent disorders were anxiety disorders (83.6\%) followed by major depressive disorder (47.3\%) and somatoform disorders (10.6\%). Comparing the outcomes of treatment on mental disorder diagnosis in each study subjects, revealed that pharmacotherapy was effective on anxiety disorders and depressive disorder but there have not been significant changes in somatoform, eating and bipolar disorders (Table 3). 
Table 1. Demographic features of the study sample $(n=55)$.

\begin{tabular}{llcc}
\hline Variables & & Number & Percent \\
\hline \multirow{3}{*}{ Sex } & Female & 22 & 40 \\
& Male & 33 & 60 \\
& Single & 2 & 3.6 \\
& Married & 51 & 92.7 \\
& Widowed & 2 & 3.6 \\
Academic Status & Illiterate and primary & 5 & 9.1 \\
& Middle school & 13 & 23.6 \\
& High school graduated & 21 & 38.2 \\
& Academic & 16 & 29.1 \\
& Unemployed & 2 & 3.6 \\
& Retired & 8 & 14.5 \\
& Housekeeper & 18 & 32.7 \\
& Worker & 3 & 5.5 \\
& Free & 11 & 20 \\
& Employee & 12 & 21.8 \\
& Student & 1 & 1.8 \\
\hline
\end{tabular}

Table 2. Comparing the mean score of psychological features of the study subjects before and after treatment.

\begin{tabular}{lccccc}
\hline & \multicolumn{2}{c}{ Before treatment } & \multicolumn{2}{c}{ After treatment } & \\
& Average & SD & Average & SD & P Value \\
\hline $\begin{array}{l}\text { Beck Anxiety } \\
\text { Inventory }\end{array}$ & 20.7 & 10.5 & 10.3 & 7.6 & 0.001 \\
$\begin{array}{l}\text { Hamilton } \\
\text { Depression Test }\end{array}$ & 25 & 9 & 4.9 & 6 & 0.001 \\
GSI & 0.83 & 0.5 & 0.49 & 0.39 & 0.001 \\
\hline
\end{tabular}

GSI: global severity index.

Table 3. The prevalence of comorbid mental disorders with chronic tinnitus.

\begin{tabular}{lccccc}
\hline Mental disorders & \multicolumn{2}{c}{ Before treatment } & \multicolumn{2}{c}{ After treatment } & P Value \\
& No. & Percent & No. & Percent & \\
\hline $\begin{array}{l}\text { Bipolar mood } \\
\text { disorder }\end{array}$ & 1 & 1.8 & 1 & 1.8 & .99 \\
$\begin{array}{l}\text { Major depressive } \\
\text { disorder }\end{array}$ & 26 & 47.3 & 4 & 7.4 & .0001 \\
$\begin{array}{l}\text { Anxiety disorders } \\
\begin{array}{l}\text { Somatoform } \\
\text { disorders }\end{array}\end{array}$ & 46 & 83.6 & 13 & 24.1 & .0001 \\
\begin{tabular}{l} 
Eating disorders \\
\hline
\end{tabular} & 1 & 1.8 & 1 & 1.8 & .99 \\
\hline
\end{tabular}

\section{The effect of medical treatment on subscales of} P-TQ

The psychosomatic side effects of chronic tinnitus were assessed by P-TQ. The results revealed that medical treatment of comorbid mental disorders was successful in improving the subscales of sleep, emotional distress, cognitive distress, intrusiveness and auditory perceptual difficulties (Table 4).
Table 4. Comparing the mean scores of subscales of P-TQ.

\begin{tabular}{|c|c|c|c|c|c|}
\hline & \multicolumn{2}{|c|}{ Before treatment } & \multicolumn{2}{|c|}{ After treatment } & \multirow{2}{*}{$\begin{array}{c}P \\
\text { Value }\end{array}$} \\
\hline & Average & SD & Average & SD & \\
\hline Cognitive distress & 51.9 & 22.8 & 42.6 & 27 & 0.05 \\
\hline Sleep disturbances & 44.2 & 34 & 33.7 & 37 & 0.03 \\
\hline Emotional distress & 53.9 & 23.6 & 40.9 & 31.1 & 0.05 \\
\hline $\begin{array}{l}\text { Emotional and } \\
\text { cognitive }\end{array}$ & 51.4 & 22 & 41.3 & 28 & 0.01 \\
\hline Intrusiveness & 52.3 & 25.9 & 44 & 29.9 & 0.01 \\
\hline Somatic complaints & 37.6 & 32.7 & 36.3 & 29.4 & 0.77 \\
\hline $\begin{array}{l}\text { Auditory perceptual } \\
\text { difficulties }\end{array}$ & 53.2 & 32.2 & 45.7 & 30 & 0.03 \\
\hline
\end{tabular}

\section{The effect of treatment on tinnitus intensity and tinnitus handicap}

The consequences of comparing the mean scores of severity of tinnitus (LMT) and the disability (THI), which were brought about before and after pharmacotherapyof mental disorders, revealed significant reduction (Table 5).

Table 5. The effect of pharmacotherapy on Tinnitus Loudness and disabilities resulting from tinnitus.

\begin{tabular}{|c|c|c|c|c|c|}
\hline & \multicolumn{2}{|c|}{ Before Treatment } & \multicolumn{2}{|c|}{ After Treatment } & \multirow{2}{*}{$\begin{array}{c}P \\
\text { Value }\end{array}$} \\
\hline & Mean & SD & Mean & SD & \\
\hline $\begin{array}{l}\text { Loudness Match } \\
\text { Tinnitus (dB, SL) }\end{array}$ & 5.72 & 4.54 & 3.97 & 3.19 & 0.01 \\
\hline $\begin{array}{l}\text { The amount of } \\
\text { disability from } \\
\text { tinnitus - THI }\end{array}$ & 58.17 & 26.03 & 39.94 & 23.46 & 0.002 \\
\hline
\end{tabular}

\section{Correlation between psychological features and tinnitus indexes}

By employing Pearson correlation coefficient analysis provided information made it manifest that disability resulted from tinnitus (THI) has the positive and significant correlation solely and merely with depression diagnosis variable. So the coexistence of depression with tinnitus adds to the disability level of tinnitus. But the comorbid mental disorder on tinnitus doesn't have a significant and meaningful effect on tinnitus severity (LMT) (Table 6).

\section{DISCUSSION}

This study shows that three months of medical treatment for comorbid mental disorders with chronic tinnitus reduces the intensity and disabilities of tinnitus. Is this due to the direct effect of psychotropic drugs on tinnitus or the result of reduction in the disabilities and the subjective perception of tinnitus?

Some studies support the first hypothesis. Shulman's study has shown that treatment with GABAergic and benzodiazepine medication results 
Table 6. Correlation coefficient index between THI and psychological features before treatment.

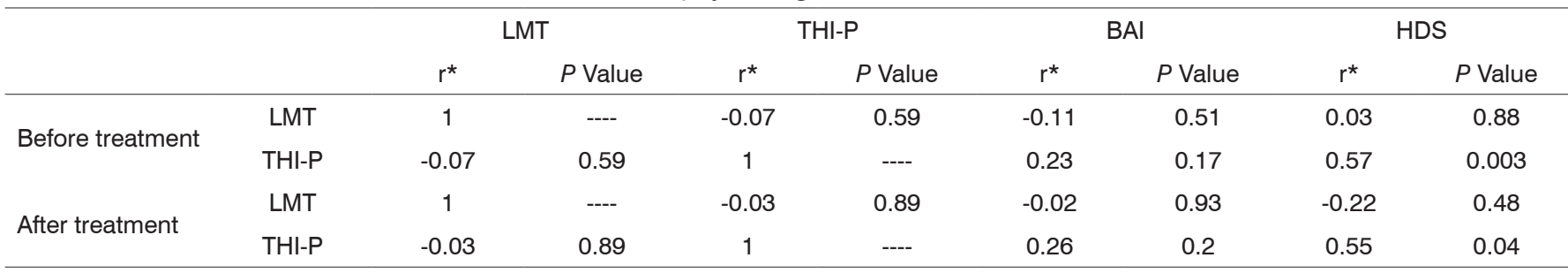

LMT: Loudness Match tinnitus; THI-P: Tinnitus handicap inventory-Persian version; BAI: Beck anxiety inventory, HDS: Hamilton depression scale. $r^{*}$ : Pearson correlation coefficient index.

in local blood flow increase in SPECT series which is accompanied by a decrease in the intensity of tinnitus ${ }^{19}$.

Neuronal discharge in epilepsy is an analogue to central stimulation of tinnitus. Prescribing antiepileptic drugs might reduce the intensity of tinnitus ${ }^{32}$. Tinnitus can be directly affected by antidepressants and mood stabilizers ${ }^{33}$.

While yet, theory that maintains the concept in which chronic tinnitus is considered to be a type of chronic stress having the potential to develop essential changes via neuronal network, was underpinned by other evidences. Dopamine receptors have a significant role in cognition and emotion. Furthermore in stress process, dopaminergic system placed in prefrontal region, medial temporal lobe and the hippocampus is strongly influenced ${ }^{34,35}$. Chronic stress via a complex neurotransmitter network can result in endocrine and autonomic hyperactivity. There is a direct pathway between the limbic system and the prefrontal area via dopamine neurotransmitter. This pathway shows that chronic stress such as chronic tinnitus can have a crucial effect on affective disorders; however, this can also be seen in other chronic physical disorders such as asthma, pain and atypical dermatitis ${ }^{36}$ and may not be specific to chronic tinnitus.

Depressive disorder is a well-known non-communicable illness with serious physical handicap and could be the one the leading causes of disability in the world in $2020^{37-39}$.Chronic tinnitus may also be severe enough to cause crucial disability in the patient ${ }^{40-42}$. Cumulative effect of both diseases would enormously reduce the quality of life and disable the patient remarkably. Therefore, diagnosing comorbid mental disorders and managing them correctly can alleviate the subjective perception of annoying and continuous sound in the ear and have positive effects on the outcome of chronic tinnitus and improve the quality of life. It can be hypothesized that exhaustion may reduce the threshold of subjective pain perception and tinnitus intensity. Comparing to a potent person whit high quality of life a frail person is more capable to percept pain and buzz sounds. Psychological aspect of subjective tinnitus has been emphasized to assess tinnitus and its disabilities.
In this study, the results prove that the subscales of TQ; emotional/cognitive disturbances and sleep problems, can be improved by treatment of anxiety and depressive disorders accompanying chronic tinnitus. In a study performed by Zoger, the results demonstrated that depression and anxiety were not directly correlated with the intensity of tinnitus, but it was efficacious in diminishing the features of tinnitus disabilities ${ }^{43}$.

\section{CONCLUSION}

Regardless of the mechanism of psychotropic agents on buzz sound of tinnitus, the study results confirmed that these agents could be effective on the intensity of tinnitus, reducing the resulted disabilities and improving the quality of life.

\section{ACKNOWLEDGEMENTS}

This study was registered and supported by the ENT and Head \& Neck Research Center, Iran University of Medical Sciences (IUMS) with collaboration of Tehran Psychiatric Institute, Mental Health Research Centre. Tehran, Iran.

\section{REFERENCES}

1. Davis AC, Rafaie EA. Epidemiology of tinnitus. In: Tyler RS, editor Tinnitus Handbook. San Diego: Singular; 2000. p.1-24.

2. Shiley SG, Folmer RL, McMenomey SO. Tinnitus and Hyperacusis. In: Cummings CW, Schuller DE, Thomas JR, Robbins KT, Harker LA, editors. Cummings Otolaryngology: Head and Neck Surgery. 4th ed. Philadelphia: Elsevier Mosby; 2005. p.2832-43.

3. Heller AJ. Classification and epidemiology of tinnitus. Otolaryngol Clin North Am. 2003;36(2):239-48. DOI: http://dx.doi.org/10.1016/ S0030-6665(02)00160-3

4. House PR. Personality of the tinnitus patient. Ciba Found Symp. 1981;85:193-203.

5. Folmer RL, Griest SE. Tinnitus and insomnia. Am J Otolaryngol. 2000;21(5):287-93. DOI: http://dx.doi.org/10.1053/ajot.2000.9871

6. Folmer RL, Griest SE, Meikle MB, Martin WH. Tinnitus severity, loudness, and depression. Otolaryngol Head Neck Surg. 1999;121(1):48-51. PMID: 10388877

7. Tyler RS, Baker LJ. Difficulties experienced by tinnitus sufferers. J Speech Hear Disord. 1983;48(2):150-4. PMID: 6621006

8. Crocetti A, Forti S, Ambrosetti U, Bo LD. Questionnaires to evaluate anxiety and depressive levels in tinnitus patients. Otolaryngol Head Neck Surg. 2009;140(3):403-5. PMID: 19248952 DOI: http://dx.doi. org/10.1016/j.otohns.2008.11.036 
9. Schleuning AJ 2nd. Management of the patient with tinnitus. Med Clin North Am. 1991;75(6):1225-37. PMID: 1943314

10. Harrop-Griffiths J, Katon W, Dobie R, Sakai C, Russo J. Chronic tinnitus: association with psychiatric diagnoses. J Psychosom Res. 1987;31(5):613-21. DOI: http://dx.doi.org/10.1016/00223999(87) $90040-7$

11. Sullivan MD, Katon W, Dobie R, Sakai C, Russo J, Harrop-Griffiths J. Disabling tinnitus. Association with affective disorder. Gen Hosp Psychiatry. 1988;10(4):285-91. PMID: 3417130 DOI: http://dx.doi. org/10.1016/0163-8343(88)90037-0

12. Malakouti S, Mahmoudian M, Alifattahi N, Salehi M. Comorbidity of chronic tinnitus and mental disorders. Int Tinnitus J. 2011;16(2):11822.

13. Asplund R. Sleepiness and sleep in elderly persons with tinnitus. Arch Gerontol Geriatr. 2003;37(2):139-45. DOI: http://dx.doi. org/10.1016/S0167-4943(03)00028-1

14. Han SS, Nam EC, Won JY, Lee KU, Chun W, Choi HK, et al. Clonazepam quiets tinnitus: a randomised crossover study with Ginkgo biloba. J Neurol Neurosurg Psychiatry. 2012;83(8):821-7. PMID: 22626945 DOI: http://dx.doi.org/10.1136/jnnp-2012-302273

15. Sullivan MD, Dobie RA, Sakai CS, Katon WJ. Treatment of depressed tinnitus patients with nortriptyline. Ann Otol Rhinol Laryngol. 1989;98(11):867-72.

16. Podoshin L, Ben-David Y, Fradis M, Malatskey S, Hafner H. Idiopathic Subjective Tinnitus Treated by Amitriptyline Hydrochloride/ Biofeedback. Int Tinnitus J. 1995;1(1):54-60.

17. Bayar N, Böke B, Turan E, Belgin E. Efficacy of amitriptyline in the treatment of subjective tinnitus. J Otolaryngol. 2001;30(5):300-3. DOI: http://dx.doi.org/10.2310/7070.2001.19597

18. Dobie RA. Depression and tinnitus. Otolaryngol Clin North Am. 2003;36(2):383-8. DOI: http://dx.doi.org/10.1016/S00306665(02)00168-8

19. Shulman A, Strashun AM, Goldstein BA. GABAA-benzodiazepine-chloride receptor-targeted therapy for tinnitus control: preliminary report. Int Tinnitus J. 2002;8(1):30-6.

20. Salvinelli F, Casale M, Paparo F, Persico AM, Zini C. Subjective tinnitus, temporomandibular joint dysfunction, and serotonin modulation of neural plasticity: causal or casual triad? Med Hypotheses. 2003;61 (4):446-8. PMID: 13679010 DOI: http://dx.doi.org/10.1016/ S0306-9877(03)00194-4

21. Robinson SK, Viirre ES, Bailey KA, Gerke MA, Harris JP, Stein MB. Randomized placebo-controlled trial of a selective serotonin reuptake inhibitor in the treatment of nondepressed tinnitus subjects. Psychosom Med. 2005;67(6):981-8. PMID: 16314604 DOI: http:// dx.doi.org/10.1097/01.psy.0000188479.04891.74

22. Sharifi V, Asaadi SM, Mohammadi MR, Amini H, Kaviani H, Semnani $\mathrm{Y}$, et al. Structured clinical interview for DSM-IV(SCID). Persian translation and cultural adaptation. Iran J Psychiatry. 2007;2(1):46-8.

23. Mahmoudian S, Shahmiri E, Rouzbahani M, Jafari Z, Keyhani M, Rahimi F, et al. Persian language version of the "Tinnitus Handicap Inventory": translation, standardization, validity and reliability. Int Tinnitus J. 2011;16(2):93-103.

24. McCombe A, Baguley D, Coles R, McKenna L, McKinney C, Windle-Taylor P.; British Association of Otolaryngologists, Head and Neck Surgeons. Guidelines for the grading of tinnitus severity: the results of a working group commissioned by the British Association of Otolaryngologists, Head and Neck Surgeons, 1999. Clin Otolaryngol Allied Sci. 2001;26(5):388-93.

25. Daneshi A, Mahmoudian S, Farhadi M, Hasanzadeh S, Ghalebaghi B. Auditory electrical tinnitus suppression in patients with and without implants. Int Tinnitus J. 2005;11(1):85-91.

26. Derogatis LR. Symptom checklist -90-R: Administration, scoring and procedures manual. Minneapolis: National Computer Systems; 1994.
27. Noorbala AA, Bagheri Yazdi SA, Yasamy MT, Mohammad K. Mental health survey of the adult population in Iran. Br J Psychiatry. 2004;184:70-3. PMID: 14702230 DOI: http://dx.doi.org/10.1192/ bjp.184.1.70

28. Mahmoudian S, Farhadi M, Gholami S, Saddadi F, Karimian AR, Mirzaei M, et al. Pattern of brain blood perfusion in tinnitus patients using technetium-99m SPECT imaging. J Res Med Sci. 2012;17(3):242-7.

29. Hamilton M. A rating scale for depression. J Neurol Neurosurg Psychiatry. 1960;23:56-62. DOI: http://dx.doi.org/10.1136/ jnnp.23.1.56

30. Beck AT, Epstein N, Brown G, Steer RA. An inventory for measuring clinical anxiety: psychometric properties. J Consult Clin Psychol. 1988;56(6):893-7. PMID: 3204199 DOI: http://dx.doi. org/10.1037/0022-006X.56.6.893

31. Asghari A, Mohammadi F, Kamrava SK, Tavakoli S, Farhadi M. Severity of depression and anxiety in obstructive sleep apnea syndrome. Eur Arch Otorhinolaryngol. 2012;269(12):2549-53. DOI: http://dx.doi.org/10.1007/s00405-012-1942-6

32. Hoekstra CE, Rynja SP, van Zanten GA, Rovers MM. Anticonvulsants for tinnitus. Cochrane Database Syst Rev. 2011;6(7):CD007960.

33. Belli H, Belli S, Oktay MF, Ural C. Psychopathological dimensions of tinnitus and psychopharmacologic approaches in its treatment. Gen Hosp Psychiatry. 2012;34(3):282-9. DOI: http://dx.doi.org/10.1016/j. genhosppsych.2011.12.006

34. Lopez-Gonzalez MA, Esteban-Ortega F. Tinnitus dopaminergic pathway. Ear noises treatment by dopamine modulation. Med Hypotheses. 2005;65(2):349-52. PMID: 15922111 DOI: http://dx.doi. org/10.1016/j.mehy.2005.02.016

35. Haab L, Wallhäusser-Franke E, Trenado C, Strauss DJ. Modeling limbic influences on habituation deficits in chronic tinnitus aurium. Conf Proc IEEE Eng Med Biol Soc. 2009;2009:4234-7.

36. Zirke N, Seydel C, Szczepek AJ, Olze H, Haupt H, Mazurek B. Psychological comorbidity in patients with chronic tinnitus: analysis and comparison with chronic pain, asthma or atopic dermatitis patients. Qual Life Res. 2013;22(2):263-72. PMID: 22430181 DOI: http://dx.doi.org/10.1007/s11136-012-0156-0

37. Penninx BW, Leveille S, Ferrucci L, van Eijk JT, Guralnik JM. Exploring the effect of depression on physical disability: Iongitudinal evidence from the established populations for epidemiologic studies of the elderly. Am J Public Health. 1999;89(9):1346-52. PMID: 10474551 DOI: http://dx.doi.org/10.2105/AJPH.89.9.1346

38. Schrepf A, Clevenger L, Christensen D, DeGeest K, Bender D, Ahmed A, et al. Cortisol and inflammatory processes in ovarian cancer patients following primary treatment: relationships with depression, fatigue, and disability. Brain Behav Immun. 2013;30 Suppl:S126-34.

39. Arterburn D, Westbrook EO, Ludman EJ, Operskalski B, Linde JA, Rohde P, et al. Relationship between Obesity, Depression, and Disability in Middle-Aged Women. Obes Res Clin Pract. 2012;6(3):e197-e206.

40. Cima RF, Vlaeyen JW, Maes IH, Joore MA, Anteunis LJ . Tinnitus interferes with daily life activities: a psychometric examination of the Tinnitus Disability Index. Ear Hear. 2011;32(5):623-33. DOI: http:// dx.doi.org/10.1097/AUD.0b013e31820dd411

41. Lim JJ, Lu PK, Koh DS, Eng SP. Impact of tinnitus as measured by the Tinnitus Handicap Inventory among tinnitus sufferers in Singapore. Singapore Med J. 2010;51(7):551-7. PMID: 20730394

42. Prestes R, Daniela G. Impact of tinnitus on quality of life, loudness and pitch match, and high-frequency audiometry. Int Tinnitus $\mathrm{J}$. 2009;15(2):134-8.

43. Zöger S, Svedlund J, Holgers KM. Relationship between tinnitus severity and psychiatric disorders. Psychosomatics. 2006;47(4):282-8. PMID: 16844885 DOI: http://dx.doi.org/10.1176/appi.psy.47.4.282 